\title{
Glycogen storage disease type 1a: a new genetic mutation found in Sri Lanka
}

\author{
A Amarasinghe ${ }^{1}$, D B Venkatesh ${ }^{2}$, R D N P Liyanage ${ }^{3}$ \\ Sri Lanka Journal of Child Health, 2004; 33: 117-8
}

(Key words: Glycogen storage disease type 1a, Sri Lanka)

\section{Introduction}

Glycogen storage disease type 1 (GSD 1) is an autosomal recessive metabolic disorder centred in the liver. In 1929 von Gierke provided the initial description of GSD 1 from autopsy reports of 2 children whose very large livers contained excessive glycogen ${ }^{1}$. In children with GSD1, a specific enzyme that breaks down glycogen is absent or deficient in hepatocytes. The subtype GSD1a is caused by deficient activity of the enzyme glucose-6phosphatase representing at least 14 distinct allelic variants. Due to the missing enzyme the body cannot generate glucose from glycogen and it is difficult to maintain normal blood sugar levels between meals without constant feeding. As a result of abnormal pathways of metabolism getting activated, elevated levels of lactate, lipids and uric acid occur. Because of abnormal accumulation of glycogen, hepatomegaly and renal enlargement can occur. The condition can cause metabolic acidosis and respiratory distress after a overnight fast ${ }^{2}$.

Children with GSD1a can develop gout and hepatic or renal tumors in later life ${ }^{3}$. They appear normal at birth but will begin to develop hypoglycaemia, hepatomegaly, developmental delay, elevated lactate and uric acid and seizures around 2-3 months of age. As GSD is rare, and sometimes has partial expression, these symptoms are not fully recognized often leading to misdiagnosis. A definitive diagnosis of GSD. requires a liver biopsy to demonstrate a deficiency of glucose-6-phosphatase activity in hepatocytes. Identification of the mutations for glucose-6-phosphatase gene allows a non-invasive diagnostic method for a majority of GSD. Currently there is no cure for GSD. Once the diagnosis is made the only way to minimize symptoms is to monitor blood sugar levels and adjust the diet accordingly.

\footnotetext{
${ }^{1}$ Consultant Paediatrician, ${ }^{2}$ Consultant Biochemist, ${ }^{3}$ Senior Paediatric House Officer, Apollo Hospitals Colombo.
}

(Received on 30 September 2004)
Follow up of these patients for complications such as hepatic, renal tumors and growth retardation is also important ${ }^{4}$. This is a report of a Sri Lankan boy who was diagnosed to have GSD 1a by genetic analysis.

\section{Case report}

A 14 year old boy of a non-consanguineous marriage presented with a history of abdominal distension since the age of 8 months. His antenatal, perinatal and neonatal history was uneventful. Abdominal distension was identified clinically and by ultrasound as due to hepatomegaly at 8 months. Since then he was investigated at several hospitals for hepatomegaly. The results of some tests done from the age of 8 months to 14 years are as follows:

Serum alanine aminotransferase (ALT) ranged from 82-191 U/L (normal 0-40 U/L). Serum protein, bilirubin, alkaline phosphatase and gamma glutamyltransferase $(\square \mathrm{GT})$ were normal. Serum cholesterol ranged from 174-288 mg/dl (normal 140$239 \mathrm{mg} / \mathrm{dl}$ ). Serum triglycerides ranged from 174-576 $\mathrm{mg} / \mathrm{dl}$ (normal 10-190 mg/dl). High density lipoproteins (HDL), low density lipoproteins (LDL) and very low density lipoproteins (VLDL) were normal. Full blood count, ESR, blood picture, coagulation profile, renal profile, serum caeruloplasmin, serum copper, alpha-1 antitripsin level and hepatitis A, B, C, E screening tests were normal. Anti nuclear factor was negative.

Two liver biopsies were done in this child. The first, done at the age of 3 years, showed moderate fatty liver and commencing fibrosis. The second, done at the age of 11 years, showed features of steatohepatitis with stage 2-3 fibrosis. However, on both occasions, a definitive diagnosis was not made. Nine ultrasound scans and one CT scan of abdomen done from the age of 1 year showed only diffuse hepatomegaly. 2D ECHO was normal. The child has been on different types of medicine during the last 13 years including multivitamins, lipid lowering agents and calcium containing drugs. 
When the child presented to Apollo hospitals in February 2004 he was completely asymptomatic except for the gross abdominal distension. His developmental milestones were normal and he had normal school performance. His weight was $27.5 \mathrm{~kg}$ and height $142 \mathrm{~cm}$. The general examination was normal except for the grossly enlarged liver which was felt $6 \mathrm{~cm}$ below the costal margin (Figures 1). He was at Tanner stage 2 in pubertal maturation. It was noted that one fasting blood glucose done in 1993 was low at $53.3 \mathrm{mg} / \mathrm{dl}$. As this child had asymptomatic hepatomegaly with almost normal investigations and a low fasting blood glucose level, glycogen storage disease was strongly suspected. Dr Deeksha Bali, GSD Laboratory Director, Duke University Medical Centre, Durham, North Carolina, USA, which is one of the few international centres for the diagnosis of GSD, was contacted regarding genetic diagnosis. The patient was admitted to the Apollo Hospitals for one day and all investigations directed at this diagnosis were carried out. Following were the results:

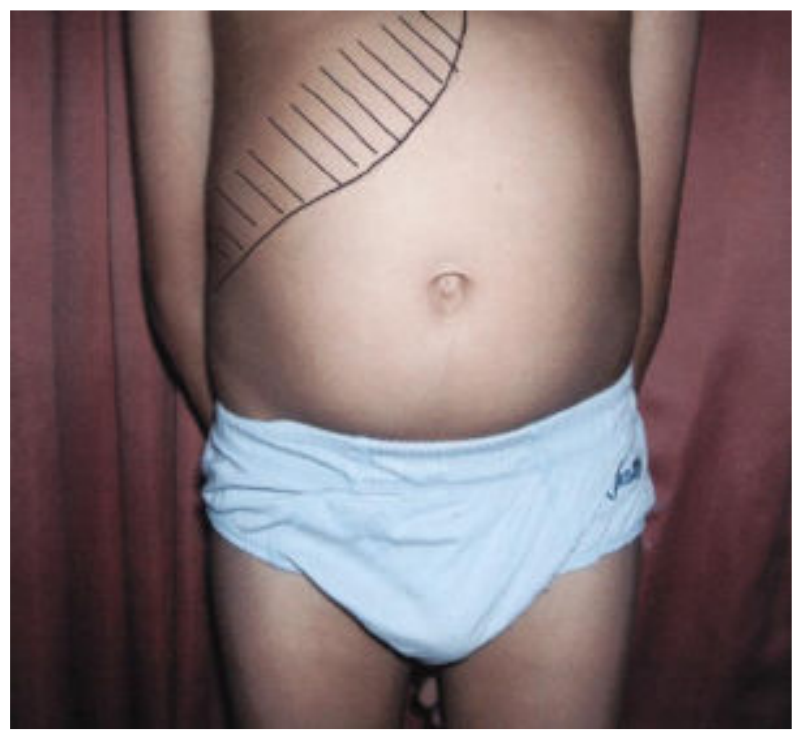

Figure 1. Grossly enlarged liver $6 \mathrm{~cm}$ below costal margin.

Full blood count, blood picture, serum proteins and renal function tests were normal. Serum ALT was $127 \mathrm{U} / \mathrm{L}$ (normal 0-40 U/L). Serum cholesterol was $287 \mathrm{mg} / \mathrm{dl}$ (normal 140-239 mg/dl). Serum triglyceride level was $576 \mathrm{mg} / \mathrm{dl}$.(normal 10-190 $\mathrm{mg} / \mathrm{dl})$. HDL, LDL and VLDL were normal. Plasma lactate was significantly high at $8.8 \mathrm{mmol} / \mathrm{L}$ (normal $0.7-2.1$ ). Serum uric acid was $10.2 \mathrm{mg} / \mathrm{dl}$ (normal 2.4-7.0).
Fasting blood sugar was marginally low at $68 \mathrm{mg} / \mathrm{dl}$ (normal range 70-110). As two liver biopsies were done earlier, child did not consent for a further liver biopsy to be done for enzyme analysis.

Blood was taken on the same day for genetic analysis of GSD, processed at Genetech Laboratory, Colombo and sent to Duke University Medical Centre, North Carolina, USA. At this centre, by genetic analysis, two mutations which lead to GSD1a viz. $580 \mathrm{G}>\mathrm{A}$ (Cys167Tyr) and 963 C $>$ T (Arg295Cys) were found. The first mutation was reported by genetists at Duke University as a hitherto undescribed/unseen one in world literature and the second mutation a rare mutation in Caucasian population ${ }^{5}$. They feel that the fact this child comes from Asia, where genetic diagnosis of children with GSD is rarely done, may have led to these rare findings.

However this patient has some unusual features such as not having significant lowering of blood sugar even after an overnight fast, as GSD 1a patients are known to have low blood sugar levels leading even to seizures and coma after such a fast. This may be due to the fact that glucose-6-phosphatase enzyme is partially present in the child. Currently the child is on a special diet under supervision of a dietician and he is being followed up for complications.

\section{Acknowledgements}

We thank Dr Deeksha S Bali, Director, GSD laboratory of Duke University Durham, North Carolina USA for DNA test done to diagnose GSD and Genetech Lab of Colombo Sri Lanka for preparing blood for dispatching to USA.

\section{References}

1. Spahr R C. von Gierke disease- a review. South Med J 1976; 69(8): 1022-8.

2. Chen Y. Glycogen storage disease - Metabolic and molecular basis of inherited diseases- 8th edNew York, McGraw-Hill, 2001; 1521.

3. Smit C P. The long term outcome of patients with glycogen storage disease. $J$ inherited metabolic disease 1990; 4: 411-8.

4. Kline G A. University of Calgary Canada Glucose 6 Phosphatase deficiency update- Feb 6 2003 e medicine.

5. Bali D S. Duke University Medical Centre Personal communication June 082003. 
